\title{
Efficacy and Safety of Vildagliptin as an Add-on to Insulin with or without Metformin in Japanese Patients with Type 2 Diabetes Mellitus: A 12-week, Double-Blind, Randomized Study
}

\author{
Takahisa Hirose · Manabu Suzuki · Isao Tsumiyama
}

To view enhanced content go to www.diabetestherapy-open.com Received: October 5, 2015 / Published online: November 30, 2015

(c) The Author(s) 2015. This article is published with open access at Springerlink.com

\section{ABSTRACT}

Introduction: To assess the efficacy and safety of vildagliptin as add-on therapy in Japanese patients with type 2 diabetes mellitus (T2DM), inadequately controlled on stable long-acting, intermediate-acting, or pre-mixed insulin, with or without concomitant metformin.

Methods: In this 12-week placebo-controlled study, patients were randomized to receive either vildagliptin $50 \mathrm{mg}$ twice daily (bid) or

Electronic supplementary material The online version of this article (doi:10.1007/s13300-015-0147-6) contains supplementary material, which is available to authorized users.

Dr. Hirose and Dr. Suzuki have contributed equally towards the manuscript and hold joint first authorship.

T. Hirose $(\bowtie)$

Division of Diabetes, Metabolism and

Endocrinology, Department of Medicine, Toho

University School of Medicine, Tokyo, Japan

e-mail: takahisa.hirose@med.toho-u.ac.jp

\section{Suzuki}

Development Division, Clinical Development, Cardio-Metabolic Clinical Franchise Department, Novartis Pharma KK, Tokyo, Japan

\section{Tsumiyama}

Development Division, Clinical Development, Biometrics and Statistical Sciences Department, Novartis Pharma KK, Tokyo, Japan placebo treatment in a 1:1 ratio. The primary endpoint was change in glycated hemoglobin A1c (HbA1c) from baseline to 12-week endpoint. Secondary endpoints included proportion of patients achieving pre-defined HbA1c targets of $\leq 6.5 \%,<7.0 \%$, and $\mathrm{HbA} 1 \mathrm{c}<7.0 \%$ in patients with baseline $\mathrm{HbA} 1 \mathrm{c} \leq 8.0 \%$ and change in fasting plasma glucose (FPG) after 12 weeks of treatment. Regular monitoring was performed to record any treatment-emergent adverse events (AEs) and serious adverse events or hypoglycemic episodes.

Results: Of the 156 patients randomized, $96.8 \%$ completed the study (vildagliptin, $n=76$; placebo, $n=75$ ). Patient demographics and clinical characteristics were comparable between the groups at baseline. Addition of vildagliptin resulted in statistically significant reductions in HbA1c after 12 weeks $(-1.01 \pm 0.06 \%)$, with a between-treatment difference of $-0.91 \pm 0.09 \% \quad(p<0.001)$. FPG levels reduced from baseline to 12 weeks in the vildagliptin group $(-1.2 \pm 0.2 \mathrm{mmol} / \mathrm{L})$, with a between-treatment difference of $-1.2 \pm 0.3 \mathrm{mmol} / \mathrm{L}$ which was significant $(p<0.001)$. The proportion of patients achieving HbA1c targets was higher with vildagliptin treatment for all pre-defined 
responder rate categories. The overall incidence of AEs was comparable between groups (vildagliptin, $46.2 \%$ vs. placebo, $43.6 \%$ ). The overall incidence of hypoglycemic events was low and all events were self-treatable without using drug therapy. No severe hypoglycemic events were reported.

Conclusion: Treatment with vildagliptin $50 \mathrm{mg}$ bid as add-on to insulin with or without metformin resulted in statistically significant reductions in HbA1c in Japanese patients with T2DM. Overall, vildagliptin was well tolerated with a safety profile similar to that of placebo in this patient population.

ClinicalTrials.gov Identifier, NCT02002221

Funding: Novartis Pharma K.K

Keywords: Hypoglycemia; Insulin; Japanese; Type 2 diabetes mellitus; Vildagliptin

\section{INTRODUCTION}

The increasing prevalence of type 2 diabetes mellitus (T2DM) poses a major health crisis globally. According to International Diabetes Federation estimates, 382 million people were affected with T2DM in 2013. This number is projected to increase up to 600 million by 2035, with Asia alone accounting for $60 \%$ of this population [1].

In Japan, approximately 7 million people aged 20-79 years are affected with T2DM and the prevalence is dramatically increasing due to lifestyle changes, genetic predisposition, and the aging population [2,3]. Mortality related to diabetes was $44 \%$ in patients aged $<60$ years in Japan, China, and other parts of the Western Pacific region [1]. The high prevalence of T2DM is associated with significant economic encumbrance, accounting for up to $6 \%$ of the total healthcare budget [3].
Due to the progressive nature of T2DM, treatment intensification with oral antidiabetes drugs (OADs) is often required. However, despite the availability of several OADs and advancements in T2DM management, achieving glycated hemoglobin A1c (HbA1c) goal of $<7 \%$ is still a challenge in most Asian countries including Japan [4]. Impaired insulin secretion and insulin resistance are two major pathophysiological features where insulin secretory response is severely impaired in T2DM patients, especially among Japanese population [5].

In Japan, insulin is now being used more frequently, with $\sim 30 \%$ of patients receiving either a monotherapy or in combination with other OADs $[6,7]$. Although pre-mixed insulin lowers fasting plasma glucose (FPG) and post-prandial glucose levels to some extent, it eventually fails to demonstrate adequate control over glycemic excursions [7]. Fear of increased risk of hypoglycemia and weight gain associated with insulin often results in delay in treatment initiation and intensification $[8,9]$. In addition, patients undergoing insulin treatment gradually develop a syndrome called Impaired Awareness of Hypoglycemia (IAH), in which the ability to identify the onset of hypoglycemia becomes progressively impaired and thus the complications associated with hypoglycemia increase $[10,11]$.

Hence, there is a need for OADs as an add-on to insulin that can improve glycemic control without increasing the risk of hypoglycemia and weight gain. Dipeptidyl peptidase-4 (DPP-4) inhibitors such as vildagliptin are being increasingly used for the treatment of diabetes in Japanese patients [12]. Further, concomitant use of insulin and a DPP-4 inhibitor has recently been included in the treatment algorithm [6]. The efficacy and tolerability of vildagliptin in combination with insulin, with or without 
metformin, has been demonstrated in randomized clinical trials in global populations including Asians [13-15]. However, there is still a dearth of data on the efficacy and safety of vildagliptin as an add-on therapy to insulin in Japanese patients with T2DM.

This 12-week, randomized, placebo-controlled study aimed to assess the efficacy and safety of vildagliptin $50 \mathrm{mg}$ twice daily (bid) add-on therapy in Japanese patients with T2DM, inadequately controlled on insulin, with or without concomitant metformin treatment.

\section{METHODS}

\section{Study Design and Patient Population}

This was a 12-week, randomized, double-blind, placebo-controlled study conducted in Japan. Patients were treated with stable once daily (qd) or bid injectable doses ( $\leq 1 \mathrm{unit} / \mathrm{kg} / \mathrm{day})$ of long-acting, intermediate-acting, or pre-mixed insulin, with or without metformin, for at least 12 weeks prior to screening. Patient visits were scheduled at week -2 (visit 1 ), week 0 , (baseline), and at weeks 4, 8, and 12 (visits 2, 3 , and 4, respectively; Fig. 1).

Following a 2-week screening period, men and women, aged between 20 and 75 years, with baseline HbA1c 7-10\%, body mass index
(BMI) $20-35 \mathrm{~kg} / \mathrm{m}^{2}$, fasting C-peptide $\geq 0.6 \mathrm{ng} /$ $\mathrm{mL} \quad(\geq 0.20 \mathrm{nmol} / \mathrm{L})$, and inadequately controlled on insulin with or without metformin, were randomized. Patients with a history of type 1 diabetes, FPG levels $\geq 15.0 \mathrm{mmol} / \mathrm{L}$, acute metabolic complications such as ketoacidosis or lactic acidosis, critical liver conditions such as cirrhosis or hepatitis, impaired renal function, congestive heart failure (New York Heart Association Class III or IV), myocardial infarction, stroke or ischemic attacks in past 6 months were excluded from the study. Patients who received rapid- or short-acting insulin except in pre-mixed formulations with either intermediate- or long-acting insulin, or even those on insulin doses taken more frequently than bid, or a total insulin dose exceeding $1 \mathrm{unit} / \mathrm{kg} /$ day for the past 12 weeks were also excluded. The dose of insulin was to be maintained within 10\% variation from baseline throughout the study unless dose adjustments were required for safety reasons. Patients were stratified based on the use of metformin and type of insulin.

\section{Efficacy and Safety Assessments}

The primary endpoint was the change in HbA1c from baseline to 12 weeks. Secondary efficacy endpoints included responder rates based on

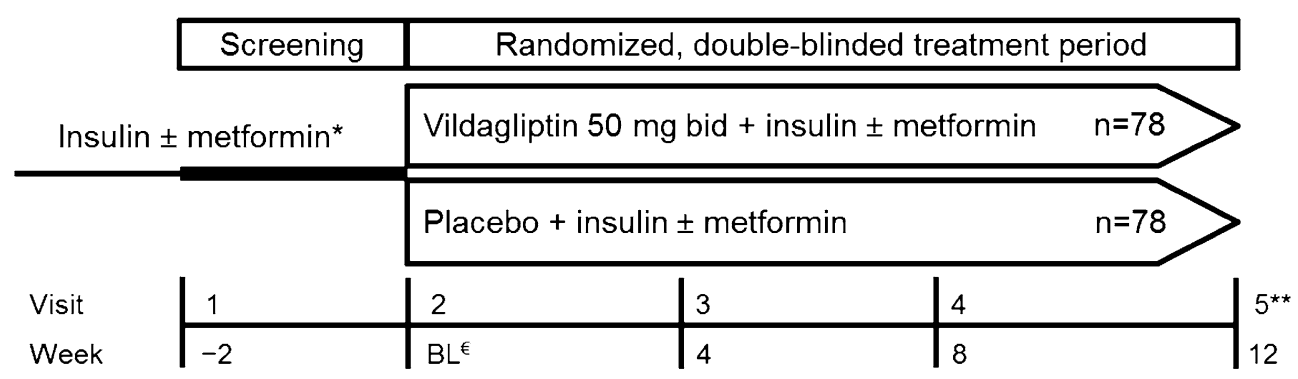

Fig. 1 Study design. *Patients continued on a stable dose of long-acting or intermediate-acting or pre-mixed insulin, and metformin if applicable, throughout the study. $B L^{€}$
Baseline, the first day of blinded study medication. ${ }^{* *}$ Each patient was instructed to visit the study site within 13 weeks from baseline. bid twice daily 
the proportion of patients achieving the pre-defined glycemic targets of HbA1c $\leq 6.5 \%$, $<7.0 \%$, and $\mathrm{HbA} 1 \mathrm{c}<7.0 \%$ in patients with baseline $\mathrm{HbA} 1 \mathrm{c} \leq 8.0 \%, \mathrm{HbA} 1 \mathrm{c}$ reduction from baseline to endpoint of $\geq 1 \%$ and $\geq 0.5 \%$, and change in FPG from baseline to study endpoint. Subgroup analysis based on concomitant use of metformin and insulin types were also performed. Safety assessments included vital signs, body weight, standard hematology, urinalysis and biochemistry test results, as well as recording and regular monitoring of treatment-emergent adverse events (AEs) and serious adverse events (SAEs). Patients were educated on hypoglycemic symptoms in the beginning of the screening period where general reviews on possible triggers and identification of symptoms were shared. At baseline visit, patients were provided with a personal calibrated home glucose monitor and were asked to record the hypoglycemic events in a glycemia study diary. Hypoglycemia was defined as symptoms suggestive of hypoglycemia that was further confirmed by a self-monitored blood glucose measurement of $<3.1 \mathrm{mmol} / \mathrm{L}$. The event was considered grade 1 if the patient was able to initiate self-treatment, and grade 2 (severe hypoglycemia) if the patient required assistance of another person or hospitalization. All laboratory assessments were performed at a central facility (LSI Medience Corporation, Tokyo, Japan).

\section{Statistical Analysis}

Assuming a withdrawal rate of 5\%, a sample size of 152 patients with T2DM treated with insulin were randomized to provide $90 \%$ power to detect a clinically significant difference of $0.6 \%$ in HbA1c change from baseline between vildagliptin and placebo at a one-sided significance level of 2.5\%. nQuery Advisor 7.0
(Statistical Solutions Ltd., Cork, Ireland) was applied for the calculation of sample size based on primary variables of change from baseline in HbA1c at the week-12 endpoint.

Efficacy analyses were performed on the full analysis set (FAS) population, comprising all randomized patients who received at least one dose of study medication and had one post-randomization efficacy measurement. An analysis of covariance (ANCOVA) model, with treatment, type of insulin (long- or intermediate-acting vs. pre-mixed), and use of metformin as classification variables and baseline HbA1c as a covariate, was used to compare the treatment effect in HbA1c reduction after 12 weeks. Changes in FPG levels from baseline to week 12 were also analyzed using ANCOVA model. The least square mean change and difference from baseline for each treatment group, and the associated one-sided 95\% confidence interval (CI) and $p$ value for each difference was obtained from the primary analysis model. The percentage of patients who met each of the pre-defined responder criteria was computed and compared using a Chi-Squared test in the FAS. For subgroup analysis, summary of absolute values and changes in $\mathrm{HbA1c}$ from baseline to study endpoint were presented on the last observation carried forward-based data for the FAS. Safety analyses were performed on the safety set which included all the patients who received at least one dose of the study drug and were summarized descriptively. All the data analysis for this study was performed using SAS $^{\circledR}$ statistical software (version 9.3, SAS Institute Inc., Cary, NC, USA).

\section{Ethics and Good Clinical Practice}

The study protocol was reviewed and approved by the Independent Ethics Committee/ 
Institutional Review Board at each participating center. All procedures followed were in accordance with the ethical standards of the responsible committee on human experimentation (institutional and national), the Declaration of Helsinki of 1964, as revised in 2013 and Good Clinical Practice guidelines. Written informed consent was obtained from all patients prior to inclusion in the study. The study is registered with ClinicalTrials.gov, identifier: NCT02002221.

\section{RESULTS}

\section{Patient Disposition and Baseline Characteristics}

A total of 275 patients were screened based on inclusion/exclusion criteria. Unacceptable laboratory values accounted for $68.9 \%(n=119)$ of screening failures. Out of 156 patients randomized, $96.8 \%$ (vildagliptin, $n=76$ and placebo, $n=75$ ) completed the study (Fig. 2). The most common reason behind discontinuation was AEs: $2.6 \%$ in the vildagliptin and $1.3 \%$ in the placebo group. Demographics and baseline characteristics of the patients are presented in Table 1. Both treatment groups were well balanced for baseline characteristics. Men predominated over women $(71.2 \%$ vs. $28.8 \%$, respectively). The overall mean age \pm SD was $59.3 \pm 9.3$ years, mean BMI was $25.7 \pm 3.3 \mathrm{~kg} / \mathrm{m}^{2}$, mean baseline $\mathrm{HbA} 1 \mathrm{c}$ was $8.1 \pm 0.8 \%$, and mean FPG was $8.9 \pm 2.6 \mathrm{mmol} / \mathrm{L}$. The mean duration of T2DM was $\sim 13$ years. More patients were on intermediate-acting insulin $(n=91)$ compared to pre-mixed insulin $(n=65)$. The mean daily doses of insulin and metformin were $0.3 \pm 0.18 \mathrm{unit} / \mathrm{kg} / \mathrm{day}, \quad$ and $1047.8 \mathrm{mg} /$ day, respectively.

\section{Efficacy}

The mean change in HbA1c over 12 weeks of treatment is represented in Fig. 3a. Vildagliptin demonstrated consistent reductions in mean HbA1c compared to placebo throughout the study. The adjusted mean change in HbA1c from baseline to study endpoint was $-1.01 \pm 0.06$ and $-0.11 \pm 0.06 \%$ in the vildagliptin and placebo groups, respectively, with a between-treatment difference of $-0.91 \pm 0.09 \% \quad(p<0.001) \quad$ (Fig. 3b). The proportion of patients achieving target HbA1c $<7 \%$ were distinctly higher in the vildagliptin group compared to placebo for all pre-defined responder categories (Table 2). Half the patients (38 out of 76) in the vildagliptin group achieved HbA1c target $<7 \%$, compared with $3.9 \%$ in the placebo group. In all the subgroups by concomitant metformin use or insulin type, vildagliptin resulted in higher HbA1c reductions than placebo (Table 3). Reductions in FPG were also consistent throughout the study (Fig. 4a). The adjusted mean change in FPG from baseline to endpoint was $-1.2 \pm 0.2$ vs. $-0.02 \pm 0.2 \mathrm{mmol} / \mathrm{L}$ in the vildagliptin and placebo groups, respectively, with a betweentreatment difference of $-1.2 \pm 0.3 \mathrm{mmol} / \mathrm{L}$ $(p<0.001$; Fig. 4b).

\section{Safety}

Vildagliptin $50 \mathrm{mg}$ bid added to long-acting, intermediate-acting or pre-mixed insulin, with or without metformin was generally safe and well tolerated. The overall incidence of AEs was similar and comparable between the vildagliptin (46.2\%) and placebo (43.6\%) groups (Table 4 ). The most frequent AEs were of the primary system organ class, "infections and infestations" with a slightly lower incidence 


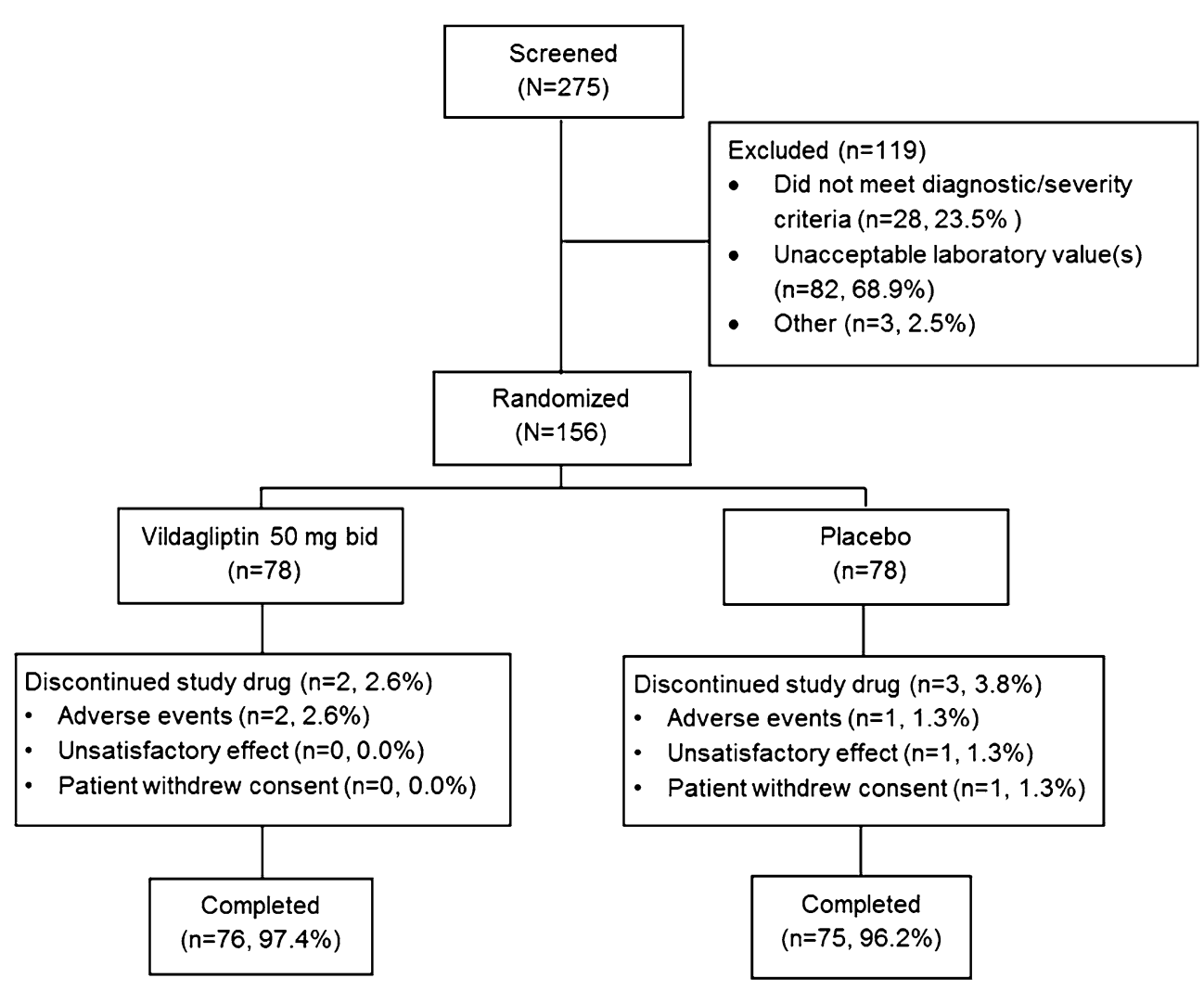

Fig. 2 Patient disposition

in the vildagliptin group compared with placebo group ( $15.4 \%$ vs. $19.2 \%$, respectively). The incidence of AEs was higher in the vildagliptin group for metabolism and nutrition disorders (6.4\% vs. $1.3 \%)$ compared with placebo. The overall incidence of AEs suspected to be drug related was higher with vildagliptin $(23.1 \%)$ compared with placebo (12.8\%), and this difference was mainly due to events of hunger and hyperhidrosis. No deaths were reported during the study. The incidence of SAEs was infrequent in either of the treatment groups $(2.6 \%$ in vildagliptin vs. $1.3 \%$ in placebo). Body weight remained almost unaltered throughout the study in the vildagliptin group $(1.09 \mathrm{~kg})$. The proportion of patients experiencing hypoglycemic events was higher in the vildagliptin group $(6.4 \%, 5$ patients) than placebo $(1.3 \%, 1$ patient). Nine hypoglycemic events were reported in the vildagliptin group as opposed to 1 event in the placebo group (Table 5). Of the 9 events, 3 were triggered by strenuous exercise, 3 events by missed/delayed meals, and the remaining 3 events had no precipitating events specified. However, there was no severe hypoglycemia or any event reported, leading to study drug discontinuation. The overall incidence of hypoglycemic events was low and all hypoglycemic events were self-treatable using non-drug therapy.

\section{DISCUSSION}

This randomized, placebo-controlled, parallel-group study is the first report to demonstrate the efficacy and safety of vildagliptin $50 \mathrm{mg}$ bid as add-on therapy in 
Table 1 Patient demographics and baseline characteristics (randomized set)

\begin{tabular}{|c|c|c|c|}
\hline Parameters & $\begin{array}{l}\text { Vildagliptin } \\
50 \mathrm{mg} \text { bid }(n=78)\end{array}$ & $\begin{array}{l}\text { Placebo } \\
(n=78)\end{array}$ & $\begin{array}{l}\text { Total } \\
(n=156)\end{array}$ \\
\hline Age (years) & $58.5 \pm 9.6$ & $60.1 \pm 9.1$ & $59.3 \pm 9.3$ \\
\hline$\geq 65$ years, $n(\%)$ & $27(34.6)$ & $28(35.9)$ & $55(35.3)$ \\
\hline Men, $n(\%)$ & $55(70.5)$ & $56(71.8)$ & $111(71.2)$ \\
\hline Body weight $(\mathrm{kg})$ & $68.9 \pm 11.6$ & $70.4 \pm 12.3$ & $69.7 \pm 11.9$ \\
\hline BMI $\left(\mathrm{kg} / \mathrm{m}^{2}\right)$ & $25.3 \pm 3.4$ & $26.0 \pm 3.1$ & $25.7 \pm 3.3$ \\
\hline HbAlc (\%) & $8.1 \pm 0.8$ & $8.1 \pm 0.9$ & $8.1 \pm 0.8$ \\
\hline FPG $(\mathrm{mmol} / \mathrm{L})$ & $9.0 \pm 3.0$ & $8.7 \pm 2.0$ & $8.9 \pm 2.6$ \\
\hline$\geq 8.9 \mathrm{mmol} / \mathrm{L}, n(\%)$ & $32(41.0)$ & $32(41.0)$ & $64(41.0)$ \\
\hline Duration of T2DM (years) & $12.8 \pm 9.0$ & $12.9 \pm 8.1$ & $12.9 \pm 8.6$ \\
\hline \multicolumn{4}{|l|}{ eGFR (MDRD), $\mathrm{mL} / \mathrm{min} / 1.73 \mathrm{~m}^{2}, n(\%)$} \\
\hline Normal, $>80$ & $65(83.3)$ & $59(75.6)$ & $124(79.5)$ \\
\hline Mild, $\geq 50$ to $\leq 80$ & $12(15.4)$ & $18(23.1)$ & $30(19.2)$ \\
\hline Moderate, $\geq 30$ to $<50$ & $1(1.3)$ & $1(1.3)$ & $2(1.3)$ \\
\hline \multicolumn{4}{|l|}{ Background therapy } \\
\hline Insulin dose (unit $/ \mathrm{kg} /$ day) & $0.3 \pm 0.17$ & $0.3 \pm 0.20$ & $0.3 \pm 0.18$ \\
\hline Insulin with concomitant metformin, $n(\%)$ & $34(43.6)$ & $34(43.6)$ & $68(43.6)$ \\
\hline Long- or Intermediate-acting, $n(\%)$ & $21(26.9)$ & $20(25.6)$ & $41(26.3)$ \\
\hline Pre-mixed, $n(\%)$ & $13(16.7)$ & $14(17.9)$ & $27(17.3)$ \\
\hline Insulin without concomitant metformin, $n(\%)$ & $44(56.4)$ & $44(56.4)$ & $88(56.4)$ \\
\hline Long- or Intermediate-acting, $n(\%)$ & $25(32.1)$ & $25(32.1)$ & $50(32.1)$ \\
\hline Pre-mixed, $n(\%)$ & $19(24.4)$ & $19(24.4)$ & $38(24.4)$ \\
\hline Metformin $(n)$ & 34 & 34 & 68 \\
\hline Metformin total daily dose (mg/day) & $1022.1 \pm 497.6$ & $1073.5 \pm 446.1$ & $1047.8 \pm 469.7$ \\
\hline$\leq 750 \mathrm{mg}, n(\%)$ & $17(21.8)$ & $11(14.1)$ & $28(17.9)$ \\
\hline$>750 \mathrm{mg}, n(\%)$ & $17(21.8)$ & $23(29.5)$ & $40(25.6)$ \\
\hline
\end{tabular}

Data are expressed as mean $\pm \mathrm{SD}$, unless specified otherwise bid twice daily, $B M I$ body mass index, eGFR estimated glomerular filtration rate, $F P G$ fasting plasma glucose, $H b A 1 c$ glycated hemoglobin, $M D R D$ modification of diet in renal disease, $S D$ standard deviation, T2DM type 2 diabetes mellitus

Japanese patients inadequately controlled on insulin, with or without concomitant metformin. In this study, vildagliptin treatment was well tolerated with a safety profile similar to placebo group and the results were consistent with earlier studies [13-15]. Vildagliptin $50 \mathrm{mg}$ bid treatment demonstrated a clinically and statistically 
(a)
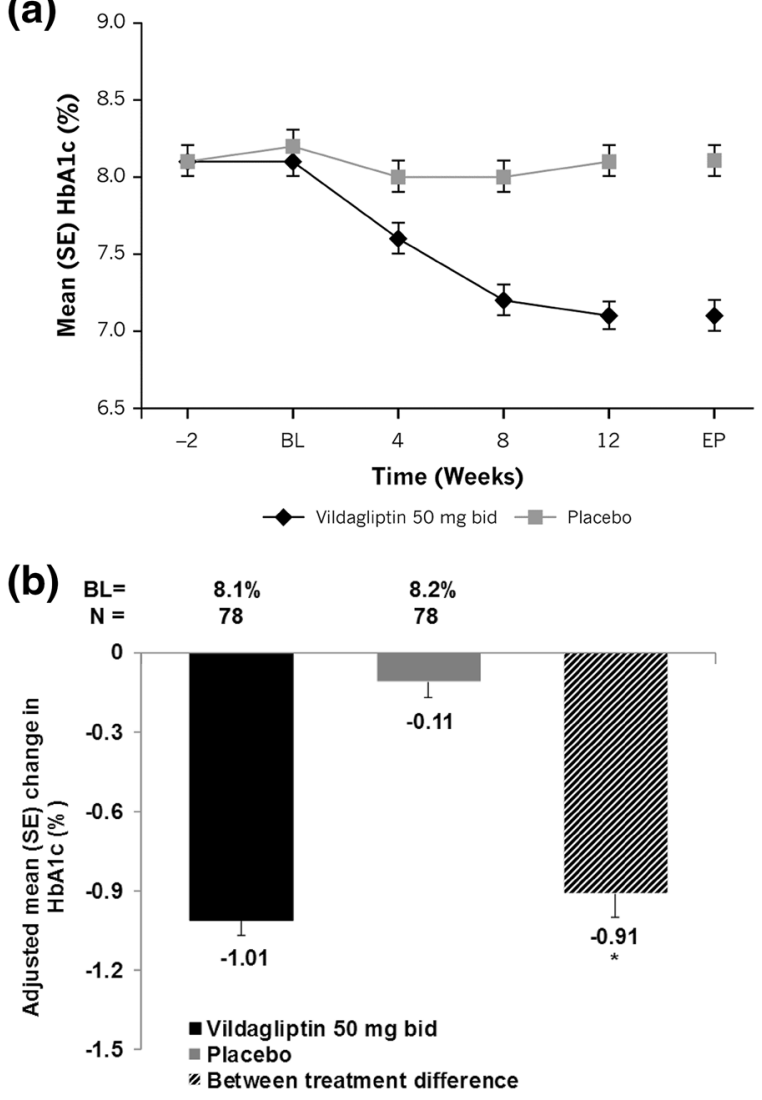

Fig. 3 a Mean HbAlc (\%) by treatment and visit. Unadjusted means and standard errors (vertical bars) are presented. Study endpoint is defined as the final available post-randomization assessment obtained at any visit (scheduled or unscheduled), prior to the start of major changes in insulin background therapy, up to the final scheduled visit including week 12 . bid twice daily, $B L$ baseline, EP endpoint, $H b A l c$ glycated hemoglobin. b Change in $\mathrm{HbAlc}$ (\%) from baseline to study endpoint. ${ }^{*} p<0.001$. Study endpoint is defined as the final available post-randomization assessment obtained at any visit (scheduled or unscheduled), prior to the start of major changes in insulin background therapy, up to the final scheduled visit including week 12 . bid twice daily, $B L$ baseline, HbAIc glycated hemoglobin, $S E$ standard error

significant $(p<0.001)$ reduction in HbA1c, with a between-treatment difference of $-0.91 \%$ after 12 weeks. Vildagliptin-mediated change in HbA1c was similar in patient subgroups treated with or without concomitant metformin. The efficacy results from this study are consistent with findings from previous trials conducted in Caucasian and Asian populations [13-15]. Vildagliptin treatment also resulted in significant reductions in FPG levels when compared with placebo, with a between-treatment difference of $-1.2 \mathrm{mmol} / \mathrm{L}$ $(p<0.001)$ which is comparable with previous findings from a 24-week clinical trial (a reduction of $-0.8 \mathrm{mmol} / \mathrm{L}$ in mean FPG from a baseline of $9.3 \mathrm{mmol} / \mathrm{L}$ ) [13]. Within subgroups based on insulin type as well as metformin use, vildagliptin demonstrated significantly marked reductions in HbA1c from baseline to endpoint, compared with placebo.

Similar and consistent differences in HbA1c values were observed in all responder rate categories. Half the patients in vildagliptin group achieved an HbA1c target $<7 \%$. Differences between treatment with vildagliptin and placebo were statistically significant for all responder rate categories.

Vildagliptin was well tolerated with overall incidence rate of AEs similar to that of placebo (46.2\%, vildagliptin vs. $43.6 \%$, placebo). The incidence of hyperhidrosis, hunger, tremor, and hypoglycemia was more common in the vildagliptin group than in the placebo group. The percentage of patients discontinued due to AEs was low and comparable between treatment groups. There were no patients with treatment-emergent hepatic enzyme elevation or deaths reported in the study. The overall incidence of hypoglycemic events was low in both the groups, but was higher in the vildagliptin-treated patients $(6.4 \%, \mathrm{HbA} 1 \mathrm{c}$ $\sim 7 \%$ ) compared with placebo-treated patients $(1.3 \%$, HbA1c $\sim 8 \%)$. None of the patients reported any severe hypoglycemia that required assistance of another person. Similar findings about a very low proportion of patients experiencing hypoglycemic events with vildagliptin treatment were reported in previous studies [13-15]. Efficacy and safety 
Table 2 HbAlc (\%) responder rates (FAS)

\begin{tabular}{lll}
\hline Responder criteria & $\begin{array}{l}\text { Vildagliptin } \\
\mathbf{5 0 ~} \mathbf{~ g} \text { bid } \mathbf{( n = 7 8 )}\end{array}$ & $\begin{array}{l}\text { Placebo } \\
(\mathbf{n}=\mathbf{7 8})\end{array}$ \\
\hline $\mathrm{N}^{\prime \mathbf{a}}$ & $78(100)$ & $78(100)$ \\
Responder criterion & & \\
At least one criterion met & $67(85.9)^{*}$ & $21(26.9)^{*}$ \\
HbAlc $\leq 6.5 \%^{\mathrm{b}}$ & $23 / 77(29.9)^{*}$ & $2 / 78(2.6)^{*}$ \\
HbAlc $<7.0 \%{ }^{\mathrm{b}}$ & $38 / 76(50.0)^{*}$ & $3 / 77(3.9)^{*}$ \\
HbAlc $<7.0 \%$ in patients with baseline HbAlc $\leq 8.0 \%^{\mathrm{c}}$ & $33 / 42(78.6)^{*}$ & $3 / 37(8.1)^{*}$ \\
HbAlc reduction $\geq 1.0 \%^{\mathrm{a}}$ & $38(48.7)^{*}$ & $5(6.4)^{*}$ \\
HbAlc reduction $\geq 0.5 \%^{\mathrm{a}}$ & $62(79.5)^{*}$ & $20(25.6)^{*}$ \\
\hline
\end{tabular}

Chi-square test for vildagliptin $50 \mathrm{mg}$ bid vs. placebo

bid twice daily, HbAlc glycated hemoglobin, FAS full analysis set

${ }^{*} p<0.001$

${ }^{a}$ Number (percentage) of patients with both baseline and endpoint HbAlc measurements, which were used as the denominator unless, specified otherwise

b Denominator includes only patients with baseline HbAlc $\geq 7 \%$ (>6.5\%) and endpoint HbAlc measurement

${ }^{c}$ Denominator includes only patients with $7 \% \leq$ baseline HbAlc $\leq 8 \%$ and endpoint HbAlc measurement

Table 3 Mean changes in HbAlc (\%) from baseline to endpoint by subgroups

\begin{tabular}{|c|c|c|c|c|}
\hline Treatment & $n$ & Baseline mean (SE) & Mean change (SE) & Range \\
\hline \multicolumn{5}{|l|}{ With metformin } \\
\hline Vildagliptin $50 \mathrm{mg}$ bid & 34 & $8.2(0.2)$ & $-1.1(0.1)$ & $(-2.2$ to -0.1$)$ \\
\hline Placebo & 34 & $8.3(0.2)$ & $-0.1(0.1)$ & $(-1.1$ to 1.2$)$ \\
\hline \multicolumn{5}{|l|}{ Without metformin } \\
\hline Vildagliptin $50 \mathrm{mg}$ bid & 44 & $8.0(0.1)$ & $-0.9(0.1)$ & $(-2.4$ to 0.7$)$ \\
\hline Placebo & 44 & $8.0(0.1)$ & $-0.1(0.1)$ & $(-1.2$ to 2.0$)$ \\
\hline \multicolumn{5}{|c|}{ Insulin type: long-acting or intermediate-acting } \\
\hline Vildagliptin $50 \mathrm{mg}$ bid & 46 & $8.0(0.1)$ & $-0.9(0.1)$ & $(-2.2$ to 0.7$)$ \\
\hline Placebo & 45 & $8.3(0.1)$ & $-0.0(0.1)$ & $(-1.2$ to 2.0$)$ \\
\hline \multicolumn{5}{|l|}{ Insulin type: pre-mixed } \\
\hline Vildagliptin $50 \mathrm{mg}$ bid & 32 & $8.2(0.2)$ & $-1.2(0.1)$ & $(-2.4$ to -0.3$)$ \\
\hline Placebo & 33 & $8.0(0.2)$ & $-0.2(0.1)$ & $(-1.1$ to 1.0$)$ \\
\hline
\end{tabular}

Baseline is the measurement obtained on day 1 or the sample obtained on an earlier visit (scheduled or unscheduled) which was closest to day 1 , if day 1 measurement is missing. Study endpoint is defined as the final available post-randomization assessment obtained at any visit (scheduled or unscheduled), prior to the start of major changes in insulin background therapy, up to the final scheduled visit including week 12

bid twice daily, $H b A l c$ glycated hemoglobin, $S E$ standard error 

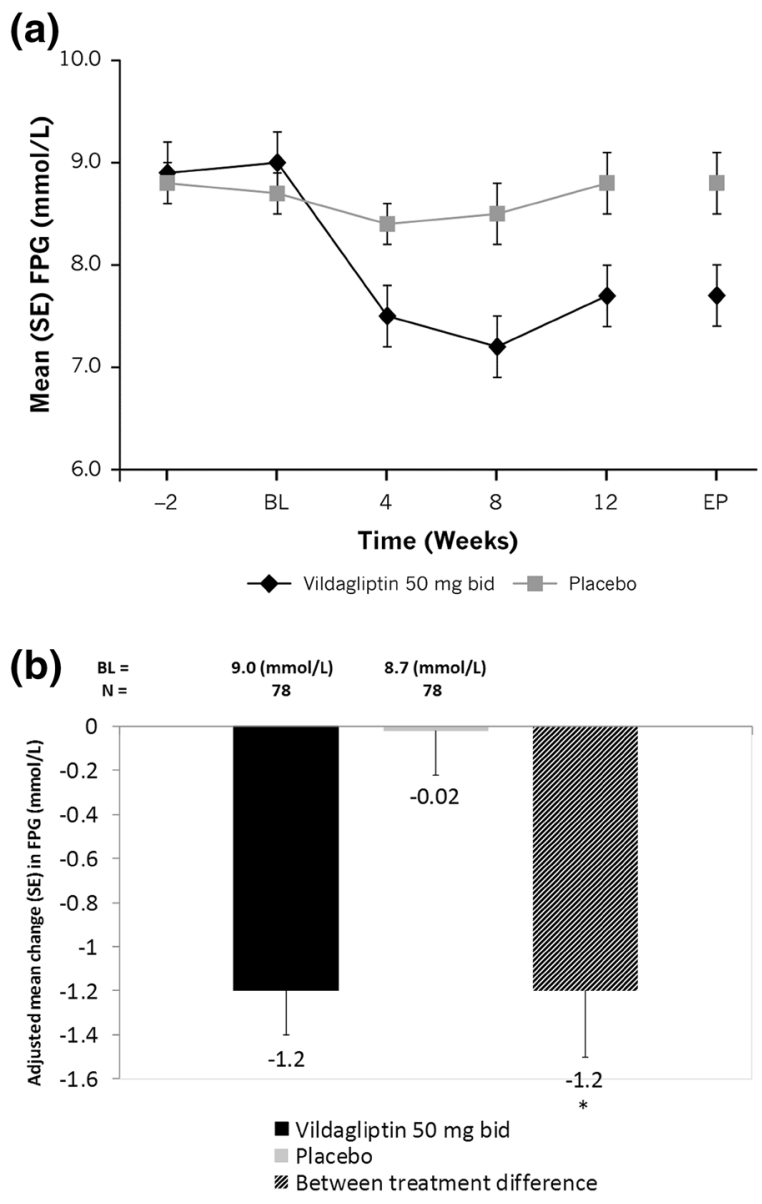

Fig. 4 a Mean FPG (mmol/L) by treatment and visit. Unadjusted means and standard errors (vertical bars) are presented. bid twice daily, $B L$ baseline, EP endpoint, FPG fasting plasma glucose. $\mathbf{b}$ Change in FPG $(\mathrm{mmol} / \mathrm{L})$ from baseline to endpoint by treatment. ${ }^{*} p<0.001$. Baseline is measurement obtained on day 1 , or the sample obtained on an earlier visit (scheduled or unscheduled) which was closest to day 1 , if day 1 measurement is missing. Study endpoint is defined as the final available post-randomization assessment obtained at any visit (scheduled or unscheduled), prior to the start of major changes in insulin background therapy, up to the final scheduled visit including week 12. bid twice daily, BL baseline, FPG fasting plasma glucose, $S E$ standard error

findings observed from this study are in line with data obtained from other gliptins including alogliptin, saxagliptin, and linagliptin as add-on to insulin in terms of effective HbA1c reduction and similar incidence rates of AEs [16-18].
Table 4 Number (\%) of patients who reported common AEs by preferred term (safety set)

\begin{tabular}{|c|c|c|}
\hline Preferred term, n (\%) & $\begin{array}{l}\text { Vildagliptin } \\
50 \mathrm{mg} \text { bid }(n=78)\end{array}$ & $\begin{array}{l}\text { Placebo } \\
(n=78)\end{array}$ \\
\hline Any preferred term & $36(46.2)$ & $34(43.6)$ \\
\hline Nasopharyngitis & $10(12.8)$ & $11(14.1)$ \\
\hline Hyperhidrosis & $8(10.3)$ & $2(2.6)$ \\
\hline Hunger & $7(9.0)$ & $3(3.8)$ \\
\hline Tremor & $7(9.0)$ & $4(5.1)$ \\
\hline Asthenia & $6(7.7)$ & $6(7.7)$ \\
\hline Hypoglycemia & $5(6.4)$ & $1(1.3)$ \\
\hline Blood glucose decreased & $2(2.6)$ & $2(2.6)$ \\
\hline Constipation & $2(2.6)$ & $1(1.3)$ \\
\hline Dizziness & $2(2.6)$ & $3(3.8)$ \\
\hline Gastroenteritis & $2(2.6)$ & 0 \\
\hline Palpitations & $2(2.6)$ & $1(1.3)$ \\
\hline Vision blurred & $2(2.6)$ & $2(2.6)$ \\
\hline Abdominal distension & $1(1.3)$ & $2(2.6)$ \\
\hline Cold sweat & 0 & $2(2.6)$ \\
\hline Miliaria & 0 & $2(2.6)$ \\
\hline Non-cardiac chest pain & 0 & $2(2.6)$ \\
\hline Pharyngitis & 0 & $2(2.6)$ \\
\hline
\end{tabular}

A patient with multiple occurrences of an $\mathrm{AE}$ under one treatment was counted only once in the AE category $A E$ adverse event, bid twice daily

Insulin therapy is generally associated with increased risk of hypoglycemia, which often is a barrier in achieving good glycemic control. Prolonged use of insulin is associated with IAH, which could also increase the risk of hypoglycemia and complications associated with it $[10,11]$. Furthermore, intensive glucose control resulted in severe hypoglycemia requiring assistance in $0.4-1.5 \%$ as reported in ADVANCE (ClinicalTrials.gov Identifier, NCT00145925) and ACCORD trials (ClinicalTrials.gov Identifier, NCT00000620) [19, 20]. 
Table 5 Number of patients who experienced hypoglycemic events by event profile and treatment (safety set)

\begin{tabular}{lll}
\hline & $\begin{array}{l}\text { Vildagliptin } \\
\mathbf{5 0} \text { mg bid } \\
(\boldsymbol{n}=\mathbf{7 8})\end{array}$ & $\begin{array}{l}\text { Placebo } \\
(\boldsymbol{n}=\mathbf{7 8})\end{array}$ \\
\hline $\begin{array}{lll}\text { Number (\%) of patients with } \\
\text { at least one hypoglycemic event }\end{array}$ & $5(6.4)$ & $1(1.3)$ \\
Number of patients with & & \\
One hypoglycemic event & $3(3.8)$ & $1(1.3)$ \\
Two hypoglycemic events & $1(1.3)$ & 0 \\
$>2$ hypoglycemic events & $1(1.3)$ & 0 \\
Total number of hypoglycemic & 9 & 1 \\
events & & $1(100)$ \\
Severity grade & & 0 \\
Grade $1^{\mathrm{a}}$ & $9(100)$ & 0 \\
Grade $2^{\mathrm{b}}$ & 0 & 0 \\
Suspected grade $2^{\mathrm{c}}$ & & \\
\hline
\end{tabular}

Data are expressed as $n(\%)$, unless specified otherwise bid twice daily

Hypoglycemic events were defined as: ${ }^{a}$ Grade 1: symptoms suggestive of hypoglycemia, where the patient was able to initiate self-treatment and plasma glucose measurement was $<56 \mathrm{mg} / \mathrm{dL}$

b Grade 2: symptoms suggestive of hypoglycemia, where the patient was unable to initiate self-treatment and plasma glucose measurement was $<56 \mathrm{mg} / \mathrm{dL}$

c Suspected grade 2: symptoms suggestive of hypoglycemia, where the patient was unable to initiate self-treatment and no plasma glucose measurement was available

In the present study, addition of vildagliptin significantly reduced $\mathrm{HbA1c}$ by $1.0 \%$ in patients treated with a stable dose of insulin. In addition, there were no occurrences of any severe hypoglycemic events, suggesting that a combination therapy of insulin and vildagliptin might be effective in achieving glycemic control without additional risk of hypoglycemia.

The use of combination therapy with insulin and incretins, including DPP-4 inhibitors such as vildagliptin could be beneficial in patients with T2DM inadequately controlled on insulin due to their complementary mechanisms of action [21].

\section{CONCLUSIONS}

Treatment with vildagliptin $50 \mathrm{mg}$ bid as add-on to insulin, with or without metformin therapy resulted in a statistically significant reduction in HbA1c in Japanese patients with T2DM. Despite significant improvement in glycemic control, few patients experienced hypoglycemic events with vildagliptin. Importantly, no patient experienced severe hypoglycemia requiring assistance of another person. The addition of vildagliptin could be an effective treatment option in Japanese patients inadequately controlled on insulin regardless of concomitant metformin therapy.

\section{ACKNOWLEDGMENTS}

The authors would like to thank the patients and staff who participated in this study. Sponsorship and article processing charges for this study were funded by Novartis Pharma K.K. The authors take full responsibility for the content of the manuscript, and they participated in all stages of manuscript development and approved the final manuscript for publication. Takahisa Hirose and Manabu Suzuki contributed to the study design, data analysis, interpretation, and drafting of the manuscript. Isao Tsumiyama contributed towards study design, data interpretation, and statistical analysis. All authors meet the International Committee of Medical Journal Editors (ICMJE) criteria for authorship, had full access to the study data and take complete responsibility for the integrity of the data and accuracy of the data 
analysis. Medical writing assistance, editorial assistance, and the collation and incorporation of comments from all authors for this study were provided by Rangan Gupta (Novartis Healthcare Pvt. Ltd., Hyderabad, India).

Disclosures. Manabu Suzuki and Isao Thumiyama are employees of Novartis Pharma KK. Takahisa Hirose is independent medical advisor for this study and has received consultancy fees, lecture fee or research funding from Novartis Pharma KK, Sanofi Eli Lilly Co., Novo Nordisk Pharma Ltd., Takeda Pharmaceutical Co. Ltd., Daiichisankyo Co. Ltd., MitsubishiTanabe Pharma Corp., DainipponSumitomo, AstraZeneca, TaishoToyama Pharmaceutical Co. Ltd., Asteras Pharma, Inc., Ono Pharmaceutical. Co. Ltd., MSD, Kissei Pharmaceutical Co., Ltd., Boehringer Ingelheim.

List of investigators/institutions. Tomio Inoue (Ageo Central General Hospital), Noritaka Onoda (Sayama Sogo Clinic), Kazunori Ogino (Ogino Clinic), Tatsuhiro Shimoyama (Shimamura Kinen Hospital), Takashi Iizuka (Asahi Internal Medicine Clinic), Koki Shin (Shin Clinic), Zenji Makita (AGE Makita Medical Clinic), Isao Uchimura (Chiyodahoujin Clinic), Masayuki Hosoi (Osaka City General Hospital), Shizuka Kaneko (Takatsuki Red Cross Hospital), Ryoko Takei (Fukuoka Teishin Hospital), Yasuyuki Kihara (Kitakyushu General Hospital), Yoshihide Fukumoto (Fukumoto Clinic), Souichi Uekihara (Japanese Red Cross Kumamoto Hospital), Shizuo Kajiyama (Kajiyama Clinic), Kojiro Ichikawa (Fukutsu Medical Clinic), Seika Kato (Hirakata Kohsai Hospital), Tatsushi Sugiura (Seiwa Clinic), Hiroaki Seino (Seino Internal Medicine Clinic), Masae Minami (Clinic Masae Minami), Yukari Shimizu
(Shimizu Clinic Fusa), Ryohei Yoshimura (Yoshimura Clinic), Fuminobu Okuguchi (Okuguchi Clinic of internal medicine), Hideo Takahashi (Minami Akatsuka Clinic), Yoshimitsu Yamasaki (Medical Corporation Kyosokai AMC Nishi-umeda Clinic), Yumiko Ide (Tokyo Center Clinic), Arihiro Kiyosue (Tokyo-Eki Center-building Clinic), Kengo Kaneko (Kumamoto Rosai Hospital).

Compliance with ethics guidelines. The study protocol was reviewed and approved by the Independent Ethics Committee/ Institutional Review Board at each participating center. All procedures followed were in accordance with the ethical standards of the responsible committee on human experimentation (institutional and national), the Declaration of Helsinki of 1964, as revised in 2013 and Good Clinical Practice guidelines. Written informed consent was obtained from all patients prior to inclusion in the study.

Open Access. This article is distributed under the terms of the Creative Commons Attribution-NonCommercial 4.0 International License (http://creativecommons.org/licenses/ by-nc/4.0/), which permits any noncommercial use, distribution, and reproduction in any medium, provided you give appropriate credit to the original author(s) and the source, provide a link to the Creative Commons license, and indicate if changes were made.

\section{REFERENCES}

1. International Diabetes Federation. IDF Diabetes Atlas. 6th ed. Brussels, Belgium: International Diabetes Federation, 2013. http://www.idf.org/ diabetesatlas/6e/diabetes. Accessed 9 Jul 2015.

2. Kawamori R. Diabetes trends in Japan. Diabetes Metab Res Rev. 2002;18:S9-13. 
3. Neville SE, Boye KS, Montgomery WS, Iwamoto K, Okamura M, Hayes RP. Diabetes in Japan: a review of disease burden and approaches to treatment. Diabetes Metab Res Rev. 2009;25:705-16.

4. Namba M, Katsuno T, Kusunoki Y, Matsuo T, Miuchi M, Miyagawa J. New strategy for the treatment of type 2 diabetes mellitus with incretin-based therapy. Clin Exp Nephrol. 2012;17:10-5.

5. Japan Diabetes Society. Treatment Guide for Diabetes. 2012-2013 Edited by Japan Diabetes Society. Bunkodo Co. Ltd. http://www.jds.or.jp/ modules/en/index.php?content_id=27. Accessed 29 Jul 2015.

6. Inzucchi SE, Bergenstal RM, Buse JB, Diamant M, Ferrannini E, Nauck M, et al. Management of hyperglycemia in type 2 diabetes: a patient-centered approach. Position statement of the American Diabetes Association (ADA) and the European Association for the Study of Diabetes (EASD). Diabetologia. 2012;55:1577-96.

7. Kadowaki T, Tajima N, Odawara M, Minamide T, Kawashima M, Yanagida D, et al. Efficacy and safety of sitagliptin add-on therapy in Japanese patients with type 2 diabetes on insulin monotherapy. Diabetol Int. 2013;4:160-72.

8. Home P, Naggar NE, Khamseh M, Gonzalez-Galvez G, Shen C, Chakkarwar P, Yang W. An observational non interventional study of people with diabetes beginning or changed to insulin analogue therapy in non-Western countries the A1chieve study. Diabetes Res Clin Pract. 2011;94:352-63.

9. Mohamed M. An audit on diabetes management in Asian patients treated by specialists: the Diabcare-Asia 1998 and 2003 studies. Curr Med Res Opin. 2008;24:507-14.

10. Noh RM, Graveling AJ, Frier BM. Medically minimizing the impact of hypoglycemia in type 2 diabetes: a review. Expert Opin Pharmacother. 2011;12:2161-75.

11. Graveling AJ, Frier BM. Impaired awareness of hypoglycemia: a review. Diabetes Metab. 2010;36:S64-74.

12. Oishi M, Yamazaki K, Okaguchi F, Sugimoto H, Kanatsuka A, Kashiwagi A, Japan Diabetes Clinical Data Management Study Group. Changes in oral antidiabetic prescriptions and improved glycemic control during the years 2002-2011 in Japan (JDDM32). J Diabetes Investig. 2014;5:581-7.
13. Kothny W, Foley JE, Kozlovski P, Shao Q, Gallwitz B, Lukashevich V. Improved glycaemic control with vildagliptin added to insulin, with or without metformin, in patients with type 2 diabetes mellitus. Diabetes Obes Metab. 2013;15:252-7.

14. Kozlovski P, Foley J, Shao Q, Lukashevich V, Kothny W. Vildagliptin-insulin combination improves glycemic control in Asians with type 2 diabetes. World J Diabetes. 2013;4:151-6.

15. Ning G, Wang W, Li L, Ma J, Lv X; all investigators, Yang M, Wang W, Woloschak M, Lukashevich V, Kothny W. Vildagliptin as add-on therapy to insulin improves glycemic control without increasing risk of hypoglycemia in Asian, predominantly Chinese, patients with type 2 diabetes mellitus. J Diabetes. 2015. doi:10.1111/ 1753-0407.12303. (Epub ahead of print).

16. Rosenstock J, Rendell MS, Gross JL, Fleck PR, Wilson CA, Mekki Q. Alogliptin added to insulin therapy in patients with type 2 diabetes reduces $\mathrm{HbA}(1 \mathrm{C})$ without causing weight gain or increased hypoglycaemia. Diabetes Obes Metab. 2009;11:1145-52.

17. Barnett AH, Charbonnel B, Donovan M, Fleming D, Chen R. Effect of saxagliptin as add-on therapy in patients with poorly controlled type 2 diabetes on insulin alone or insulin combined with metformin. Curr Med Res Opin. 2012;28:513-23.

18. Yki-Järvinen $\mathrm{H}$, Rosenstock J, Durán-Garcia $\mathrm{S}$, Pinnetti S, Bhattacharya S, Thiemann S, Patel S, Woerle HJ. Effects of adding linagliptin to basal insulin regimen for inadequately controlled type 2 diabetes: $a \geq 52$-week randomized, double-blind study. Diabetes Care. 2013;36:3875-81.

19. ADVANCE Collaborative Group, Patel A, MacMahon S, Chalmers J, Neal B, Billot L, et al. Intensive blood glucose control and vascular outcomes in patients with type 2 diabetes. $\mathrm{N}$ Engl J Med. 2008;358:2560-72.

20. Action to Control Cardiovascular Risk in Diabetes Study Group, Gerstein HC, Miller ME, Byington RP, Goff DC Jr, Bigger JT, et al. Effects of intensive glucose lowering in type 2 diabetes. $\mathrm{N}$ Engl J Med. 2008;358:2545-59.

21. Ahrén B. Insulin plus incretin: a glucose-lowering strategy for type 2-diabetes. World J Diabetes. 2014;5:40-51. 